\title{
ULUSLARARASI HUKUKTA HAZAR'IN STATÜSÜ SORUNU
}

\author{
Selçuk ÇOLAKOGLU*
}

Hazar Denizi ${ }^{1}$ yaklaşık $371.000 \mathrm{~km}$ karelik bir alanı kapsayan, denizlerle ve okyanuslarla nehir-kanal şebekesi dışında herhangi bir doğal bağlantısı bulunmayan bir tuzlu su kitlesidir. Volga ve Don nehirlerinin kollarına eklenen kanallar aracilığıyla Karadeniz ve Baltık Denizi'ne bağlanmıştır. Hazar Denizi kıyılarının kuzeyden güneye uzunluğu yaklaşık $1.200 \mathrm{~km}$ olup, doğudan batıya genişliği de $210 \mathrm{~km}$ ile $490 \mathrm{~km}$ arasında değişmektedir. Hazar Denizi'ne 10 büyük akarsu dökülmektedir (Schofield, 1996:75).

Uzun yıllar boyunca sürekli düşme gösteren Hazar'ın su seviyesi 1977 'den sonra aniden yükselmeye başlamıştı. Ortalama su seviyesi 1977 'den bu yana'yaklaşık 2 metre yükselmiştir ve halen de her yll $10-15 \mathrm{~cm}$ yükselmektedir. Bu durum ciddi ekonomik zararlara neden olmuştur. Kıyı şeridideki birçok köy su alunda kalmış ve balıkçılıkta ciddi kayıplar olmuştur. Kazakistan'daki alanlar yavaş yavaş su altında kalmakta ve bu durum ciddi sorunlar doğurmaktadır. Kazakistan'ın kuzey kıyı şeridindeki $1000^{\prime}$ in üzerinde petrol kuyusu bu yüzden işe yaramaz hale gelmiştir ve bu kuyulardan Hazar'a petrol sızmaktadır. (Gustafson, 1995:8)

Hazar havzası doğal kaynaklar açısından oldukça zengindir. Hazar'da balıkçılık önemli bir gelir kaynağıdır. Bölge dünya havyar ihtiyacının yüzde 90'ını karşılamaktadır (Bilici, 1998:43). Bunun yanısıra Hazar'da 163 milyar varil petrol ve 17.6 milyar metreküp doğalgaz rezervi vardır (Clawson, 1997-98:17). Bu da 1996 rakamlarıyla dünya petrol rezervinin yüzde 16 'sı ve dünya doğalgaz rezervinin yüzde 12 'sine denk gelmektedir.

1991 'e kadar Hazar'a tartışmasız olarak sadece Çarlık Rusyası/Sovyetler Birliği ve Iran kıyıdaş devletler olmuştur. Sovyetler Birliği'nin dağılmasından sonra onun halefi durumundaki Azerbaycan, Kazakistan, Rusya ve Türkmenistan kıyıdaş devlet durumuna

\footnotetext{
*Adnan Menderes Universitesi Nazilli IIBF Uluslararası llişkiler Bölümü Araştırma Görevlisi

${ }^{1}$ Buradaki deniz sıfatı hukuksal bir kullanım olmayıp sadece tarihsel kullanımı yansitmaktadır.
} 
gelmiş ve böylece Iran'la birlikte kıyıdaş devletlesin sayısı beşe yükselmiştir. Yeni kıyıdaş devleulerle birlikte Haz'ar'ın hıkuksal statüisü tartışmaları da gündeme geldi. Zengin petrol ve doğalgaz yataklan dolayisıyla Hazar sadece kıyıdaş devletlerin değil tỉm dünyanın ilgi alanı olmuştur. Hazar'ın hukuksal statiisünün belirlenmesi konusu esasen 1994 yılından itibaren uluslararası bir sorun haline gelmiştir. Azerbaycan Hükümeti Eylul 1994'te Amerikan ve Avrupa şirketlerinin oluşturduğu bir konsorsiyumla 8 milyar dolarlık bir anlaşma imzalamışır. Pek çok yorumcu tarafından "Yüzyılın Anlaşması" olarak nitelendirilen bu girişim ile Bakü'ye bitişik kıyılardaki Güneşli, Çırak ve Azeri sahalarından 4 milyar varil petrol çıkartılması óngörülmektedir. Bu üç sahanın üç yıllık donemde 511 milyon ton ham petrol üretilecegi umulmaktadır (Lenczowski, 1997:113). Azerbaycan Eylül 1994 tarihli petrol anlaşmasından sonra 1995 ve 1996 yıllarında uluslararası konsorsiyumlarla sonuçlandırdığı üç ayrı anlaşma daha imzalamıştır (Croissant, 1996-97:24). Azerbaycan'ı 'Tengiz petrol sahasının ihaleleri ile Kazakistan takip etmiştir (Lenczowski, 1997:115). Diğer kıyıdaş devletlerden Rusya ve tran ise bu ihalelere tepki gőstererek Hazar'in statüsü sorununu sürekli olarak güindemde tutmaya başlamışlardır.

Bu durum Hazar'ın statüsünün belirlenmesinde uluslararası hukukun yanında siyasi ve ekonomik unsurları da devreye sokmuştur. Bu yüzden her kıyıdaş devlet kendi hukuksal tezini oluştururken diğer kıyıdaş devletlerin yanında üçüncü devletlerin de destełini almaya çalışmaktadır.

Hukuksal statüsünün belìlenmesi açısından ill: olarak Hazar'ın bir göl mü yoksa bir deniz mi olduğunun saptanması gerekmektedir. Hazar deniz olarak kabul edildiği taktirde, 1982 Birleşmiş Milletler Deniz,Hukuku Sïzleşmesi'ne (BMDHS) göre, her kıyıdaş devletin karasuları, kıta sahanlığı ve münhasır ekonomik bölgesinin olması gerekmektedir.

Hazar gol olarak kabul edilirse, bu durumda ulusal sınurların belirlenmesinde iki yőntem ortaya çıkmaktadır. Bunlardan birincisi Hazar'ın tamamen ulusal sektơrlere bölünmesi, ikincisi ise ortak kullanımdır.

Statü sorununu çözưme kavuştuṛmada öncelikle Hazar'a ilişkin yapılmı̧ antlaşmalar, ikinci olarak da bỏlgesel yapılageliş (teamül) kuralları büyük önem taşımaktadır: Uluslararası hukukta Hazar için örnek tes:ikil edebilecek benzer durumlar da sorunun çözümüne yardımcı olacaktır.

\section{Ilgili Antlaşmalara Göre Hazar'ın Statüsü}

1991 yılına kadar Hazar'a kıyıdaş olan iki devlıt Çarlık Rusyası/Sovyetler Birliği (1917'den sonra) ile Iran arasında dört adet ikili antlaşma yapılmışur. Sovyetler Birliği'nin 1991'de dağılmasından sonra ise genel nitclikli başka antlaşma yapılmamışur.

10 Şubat 1828 Türkmençay Antlaşması: Antlaşmanın 4. maddesi Rusya ile Iran arasındaki sınırın Hazar'da sona erdiğini ifade etmekte, 8. maddesi ise sadece Rusya'nın Hazar'da savaş gemisi bulundurma hakkına sahip oldư̆unu belirtmektedir (Schoficld 1996:78). Boylece Hazar, kara sınırının tespitinde ölçü olarak alınmışur.

26 Şubat 1921 Moskova Dostluk Antlaşması: 11. madde ile Iran'ın Hazar'da donanma bulundurmasını engelleyen Türkmençay Antlaşması iptal edilmiştir. 
Iki taraf Hazar'da kendi bayraklan altunda seyrüsefer konusunda eşit haklara sahip olacaklardi (Dabiri, 1994:30-31).

27 Ağustos 1935 Tarihli Antlaşma: Antlaşmanın 14. ve 15. maddelerinde Sovyet ve Iran gemileri için serbest seyrüsefer hakkı ile 10 millik bir mühnasır balıkçılık alanı kurulması ơngörülmüştür. Ancak resmi sınır tayin edilmemiş̧ir. Anlaşmaya dair nota teatisinde Hazar bir "Sovyet-Iran Denizi" olarak zikredilmiştir (Schofield, 1996:78).

25 Mart 1940 Tahran Antlaşması: Bu antlaşma büyük olç̧ìde 1935 Antlaşması'nın hükümlerini teyit etmektedir. 12. Maddenin 4. fikrası ile 10 mile kadar olan sularda balıkçılık haklarının kıyı devletinin bayrağını taşıyan gemilere ait olduğu kaydedilmektedir (Dabiri, 1994:31)

Bu antlaşmaların hiçbirisi Hazar'da Sovyet Sosyalist Cumhuriyetleri Birliği (SSCB) ve Iran arasındaki sınırı belirlemediği gibi, ortak kullanım konusunda da bir hüküm içermemekte, sadece seyrüsefer ve balıkçıllıla ilgili konuları düzenlemektedir. Mevcut antlaşmaların yetersizliğinden dolayı, antlaşmalar hukukuna gore Hazar'in statüsünü çözmek mümkün değildir. Bu yüzden Hazar'a kıyıdaş devletlerin bugüne kadarki uygulamaları büyük önem taşımaktadır. Bölgesel yapılageliş kurallarına Hazar'ın göl veya deniz olma tarışmalarında değinilecektir. Bundan önce kıyıdaş devietlerin iradelerini açık bir şekilde ortaya koyan hukuksal tezlerine değinmek gerekmektedir.

\section{Kıyıdaş Devletlerin Hazar'ın Statüsü Konusundaki Görüşleri}

\section{A. Azerbaycan}

Azerbaycan Hazar'ın bir "sınır gölü" olduğu düşuncesinden hareketle, orta hat (median line) esasına göre beş ulusal sektöre bölünmesini savunmaktadır. Azerbaycan Hazar'ın sularının ve deniz dibinin tamamen taksim edilerek, egemenlik alanlanna bölünmesini ve her ülkeye ait alanda mülkiyet ve egemenlik ilkelerine dayalı olarak o ülke mevzuaunın geçerli olmasını savunmaktadır.

Azerbaycan ikinci bir teklif olarak Hazar'a "açık deniz" statüsünün uygulanabileceğini ileri sürmektedir. Bu durumda Hazar'a 16 Kasım 1994'te yürürlüğe giren 1982 BMDHS'nin uygulanmasını istemektedir. Böylece her kıyıdaş devlet 12 millik karasuları, 200 mil veya daha fazla kıta sahanlığı ve 200 millik münhasır ekonomik bölgeye sahip olacakur (Gökay, 1988:57).

Azerbaycan açısından onnem taşıyan nokıa Hazar'ın göl veya deniz statüsünde tanınmasından çok, kıyı ülkelerinin deniz üzerinde münhasır yetkilerini kullanabileceğ ulusal egemenlik alanlarına bölünmesidir. Ancak Hazar'ın hukuksal statüsü kesin olarak belirleninceye kadar, Azerbaycan her kıyı devletinin kendi bölgesinde kalacak petrol ve dogalgaz rezervlerini işletebilmesini savunmaktadır. Azerbaycan, 6 Temmuz 1998'de Rusya ve Kazakistan'ın imzaladıkları ve Hazar'ın deniz tabanını bölen anlaşmayı olumlu bir gelişme olarak değerlendirdi (Aksay, 1998b:8). Ancak Bakü, bu paylaşımı yeterli bulmayıp deniz tababının üstündeki tüm su kütlesinin de ulusal sektörlere bölünmesi gerektiợi görüşünü tekrarladı. 


\section{B. Rusya}

Hazar'ın statüsünün belirlenmesinde tarihi, stratejik, siyasi ve ekonomik sebeplerden ötürü en etkili olabilecek devlet Rusya Federasyonu'dur. Ancak Rusya bugüne kadar üç temel 'politika değişikliği yapmıştır.

Rusya Federasyonu, Hazar'ın hukuki statüsïnün 1921 ve 1940 yillannda SSCB ve Iran arasında imzalanan anla ̧̧malarla belirlenmiş olduğunu ve sözkonusu anlaşmalarda münhasır egemenlik alanınırı yalnız balıkçılık işin tanınan 10 millik kıyı şeridinden ibaret olduğunu, bunun, dışında kalan bölgelerdeki suların ortak kullanıma açık olduğunu ve Hazar Denizi'ne kıyıdaş ï.lkelerin bu sulardan eşit haklarla yararlanabileceğini ileri sürmektedir. Rusya'nın birinci tutumu 10 veya 12 veya 20 millik kıyı şeridi dışındaki su kütlesini ve deniz tabanının ortak kullanılacağı şcklindedir (Gustafson, 1995:15). Bu çerçevede Rusya, Hazar'ı kajıalı bir su sezervi olarak tanımakta, 1982 Deniz Hukuku Sozleşmesinin Hazar'a uygulanamayacağını belirtmektedir (Akimov, ?:1). Rusya ozellikle bu tezini Ağustos 1993 'ten sonra kesin bir şekilde dile getirmeye başlamışur (Gustafson, 1995:15).

Rusya'nın ikinci konuınu 12 Kasım 1996'dan itibaren 40-45 millik kıyı şeridi dişında ortak kullanım şeklindedir (Croissant, 1996-97:35). Bobylece Rusya Hazar'ın bölünmesini kabul yönünde bir adım daha atmıştır.

Rusya Şubat 1998'den sonra üçüncü bir tulum benimsemiştir. 9-10 Şubat 1998 tarihinde Rusya ve Kazakisıan Hazar'ın statüsüne ilişkin bir uzlaşma metni kabul etmişlerdir (Arystanbekova, 1998:2). Buna göre taraflar Hazar'ın deniz tabanını eşit uzaklık ilkesine göre tamamen bölmüşler, sı kültesini ise ortak kullanıma bırakmışlardır. Fakat kıyıdaş dəzvletlerin Hazar üzerinde sahip olacakları ulusal sektörler konusunda bir açıklama yapılmıamıştır. Ayrıca taraflar Hazar'ın Rusya-Kazakistan kısmının silahsızlandựı masını ve çevre, ulaşım gibi konularda işbirliği yapmayı taahhüt etmişlerdir. Mevcut bilgilerden anlaşma ile deniz tabanı ve toprak alu madenlerin araşturılması, işletilmesi, çevre koruması ile seyrüsefer konularının taraflanın saptayacağı ortak bir rejime tại tutulmasının öngörüldüğü anlaşılmaktadır.

Bu metin Rusya ve Kázakistan Cumhurbaşkanları Boris Yeltsin ve Nursultan Nazarbayev'in onayı ile Nisaı $1998^{\prime}$ de iki ülke arasında bir anlaşma taslağı haline getirildi (Aksay, 1998a:8). Bu isnlaşma 6 Temmuz 1998 tarihinde Yeltsin ve Nazarbayev tarafından Moskova'da imzalındı (Akgün, 1998:17). Böylece Rusya'nın "deniz dibi bölünebilir ama su kültesi ve su yüzeyi ortak kullanıma tabidir" görửsünü benimsediği görülmektedir (BBC, 1998a:6).

Rusya'nın üçüncü tutumıyla Hazar için "ortak su kültesi" tanımından "sınır gölü" tanımına yaklaş̧ı̆̆ı görülmektedir. Rusya Kazakistan ile yapılan sözleşmenin Hazar'da yeni bir statü oluşturacağını kabul eimese de durum pek değişmemektedir (Bilici, 1998:44). Ancak herşeye rağmen K'usya Hazar'ın tam paylaşılmasını kabul etmiş değildir. Aynca Hazar'a deniz hukukunun uygulanmasına da şiddetle karşı çıkmaktadır. Bu karşı çıkışın temelinde siyasi vè ekonomik gerekçelirin yanında hukuksal bazı saikler vardır.

Rusya, Baltuk Denizi ve Karadeniz'le bağlantuyı sağlayan Don-Volga ve VolgaBaltık kanalları yüzünden de Hazar'ın iç deniz stătüsünde değcrlendirilmesine karşı çıkmaktadır. Rusya bu kanılllardaki geçiş rejimini kendi ulusal mevzuatıyla 
düzenlemektedir. Hazar için 1982 BMDHS'nin Kısım 10'daki "iç deniz" tanımı uygulanırsa bu kanallar uluslararası suyolu haline gelecektir (Gündüz, 1994:330). Bðylece Hazar'a kıyıdaş devletlerin bu su kanallarından transit geçis hakkı dogacaktır (Dion, 1998:81). Rusya, Hazar'ı Baltık Denizi'ne ve Karadeniz'e bağlayan su kanallarının yapay su kanalı olması dolayısıyla, bu kanallar ve nehirlerin uluslararası hukukun konusu olmadıklarını iddia etmektedir (Nugman, 1998:84). Aynca Hazar hukuksal açıdan kapalı deniz olarak' değerlendirilse bile, karasulanndan zararsız geçiş ve münhasır ekonomik bölgeden serbest geçiş haklanndan sadece kıyıdaş devletler yararlanabilecektir.

Rusya'nın Hazar'ın sektörel bölünmesini engellemek için ileri sürdüğü diğer bir resmi gerckçe ise tam bir (deniz tabanı, su kütlesi) bölünmenin doğal çevreye zarar vereceğidir. Moskova Hazar'ın korunması gereken çok hassas ve esssiz bir doğal çevreye sahip olduğunu iddia etmekte, eğer Hazar scktörlere bölünecek olursa bunun neden olacă̆ı çevresel kirlenmeden korunması gerekecck olan bir balıkçılık sanayiinin varlığını gündeme getirmektedir. Ortak denetimin, denizin doğal kaynaklannı ozzellikle de Rusya ve Iran arasındaki antlaşmalarca güvence altına alınmış balıkç̧ıı haklannı daha iyi koruyacağı iddia edilmektedir. Rusya'nın çcvreyi korumak için ortaya çıkan bu yeni arzusu gerçekçi gözzükmemektedir. Çünkü Sovyet dönemi boyunca Hazar çevre açısından dünyadaki en tehlikeli bölgelerden birisi olmuştur. Gerçekten Azerbaycanlı bilim adamlanna göre Bakü ve Sumgait'i içeren Apşeron Yarımadası Hazar'ın en çok kirlenen bölgesi olmuştur (Croissant, 1996-97:30-31).

Rusya, sorunu zaman zaman BM'e de taşımışur. Özellikle Rusya, diğer kıyıdaş devletlerden Azerbaycan ve Kazakistan'ın çokuluslu şirketlerle yatığı petrol anlaşmalarını BM nezdinde kınamışur.

Rusya, 5 Ekim 1994'te deniz hukukunun diğer denizlerle doğal bağlantısı olmadı̆̆ından Hazar'a uygulanamayacağını, Hazar'ın yasal rejimini belirleyen tran'la yapılmış olan Sovyet dőnemi antlaşmalarının yürürlükte olduğunu ve böylece ortak kullanımın tck çözüm olduğunu açıklayan bir memorandumu BM'de yayınlamıştır (Croissant, 1996-97:34). Bu memorandum ayrıca herhangi bir kıyıdaş devletin tek taraflı eyleminin kabul edilemeyeceğini bildirmiştir.

\section{Kazakistan}

Kazakistan Hazar'in statüsü konusunda Şubat 1998'e kadar Azerbaycan ile benzer görüşleri benimsemiştir. Bu çerçevede Kazakistan Hazar'ı bir iç deniz olarak nitelemiş ve 1982 BMDHS'nin uygulanmasını istemiştir (Shoumikhin, 1996a:3). Kazakistan için kendi petrol ve doğalgaz sahalarındaki egemen halklarının tanınması büyük önem taşımaktadır.

Kazakistan ve Azerbaycan'ın görüşleri karşılaşı̧ııldığında, Azerbaycan'ın Hazar'ın tümüyle ulusal sektörlere bölünmesini savunurken, Kazakistan'ın deniz yatağının paylaşılması, Hazar'ın sularının ise belirli bir münhasır yetki alanı dışında ortak kullanılmasını benimsediği görülmektedir (Gökay, 1998:58).

Kazakistan ve Azerbaycan arasındaki bu küçük tutum farklılığı Kazakistan'ın Rusya ile Temmuż 1998'de anlaşma amzalamasını kolaylaştırmış̧ır. Kazakistan, deniz tabanının tamamen bölünmesini kabul ederken su kütlesinin ortak kullanılmasını kabul etmekle, Hazar'ı bir ṡınır gölü olarak değcrlendirdiği izlenimi vermektedir. Çünkü Hazar'a 
deniz hukuku uygulansaydı, kıyı devletlerinin tam egemenliğinin olduğu 12 millik karasulan dışında, 200 millik veya karşı kıyıdaş devletin sınırına kadar münhasır ekonomik bőlgeye sahip olacaktu.

\section{Iran}

Rusya gibi tran da Hazar'ın ulusal sektörlere bőlünmesine şiddetle karşı çıkmaktadır. Iran, Hazar'ın bir göl olduğunu ve beş kıyıdaş devlet tarafından ortaklaşa kullanıması gerektiğini sőylenıekte ve üçüncü devleılerin Hazar'dan yararlanmasına karşı çımaktadır. Azerbaycan ve Kazakistan'ın Hazar'ın kaynaklarını tek taraflı olarak işletmesini de eleştirmektedir (Akimov, ?:2). Iran'a gőre 1940 Antlaşması 10 millik kıyı şeridi dışında ortak kullanın ilkesini benimsemiştir (Dabiri, 1994:33). Iran, ortak kullanıma ilişkin olarak Hazır'ın 12 ulusal sektöre bölünmesini onermektedir (Dion, 1998:82). Vance Owen'ın 10 kantonluk Bosna planına benzeyen bu óneri, çok karışık ve uygulanması oldukça zordur.

Iran uzun süre, Rusya'nın tezini desteklemekle birlikte Temmuz 1998'de imzalanan Rusya-Kazakistan Anlaşması ile Iran ve Rusya'nın Hazar'daki yollan ayrılmıştır. Iran, Rusya ve Kazakistan'ın Hazar'ın deniz dibini aylaşmalarını Mayıs 1998'de BM nezdinde protesto etuniştir (BBC, 1998c:11). Iran bu protestosunda, Hazar' in beş kıyı devlctinin nzası olmaksızın paylaşılmasının kabul edilemeyeceğini ve tüm eski Sovyet cumhuriyetlerinin Sovyetler Birliği ve Iran arasında yapılan 1921 ve 1940 antlaşmalarıyla bă̆̆ı olduğunı tildirmiştir. Ayrica Iran, Türkmenistan ile 7 Temmuz 1998'de (Rus-Kazak Anlaşması'ndan bir gün sonra) ortak bir bildiri yayınlayarak Moskova ve Astana'nın imzalaūıklan anlaşmayı reddetmiş ve Hazar'ın ancak tek hukuksal statüsü olabileceğini, kaynakların da adil ve eşit bölüşülmesi gerektiğini belirtmiştir (Radikal, 1998:10).

Iran, Rusya Federasyonu'nun bu politika değişikliği ile, Hazar'a ilişkin politikasında yalnız kalmışır. Iran'ın bugün Rusya ile uzlaşı̆̌ı tek noktanın Hazar'dan boru hatı geçirilmemesi olduğı sỉylenebilir. Diğer kıyıdaş ülkelerin statü konusunda bir uzlaşmaya varmaları halinde, Iran'ın bu gelişmenin dışında kalamayacağı düşünülmektedir. Ancak Rusyı ile birlikte bir çok sorunlar yaratarak Hazar'daki petrol yataklarının işletilmesini güçleştirebilecektir.

Aslında hukuksal açıdarı Iran'ın bu iddiaları güçlü değildir. Çünkü, Iran 199l'den once 10 millik kenđi kıyı şeridi dışındaki alanı fiilen Sovyetler Birliğginin kullanımına terk etmiştir. Bugün Azerbaycin ve Kazakistan'ın kendi kıyılarına yakın alanda petrol çıkarmasına karşı çıkan Iran, Sovyet đöneminde Bakü açıklarında Moskova tarafından petrol çıkarılmasına sessiz kalmıştır (Dabiri, 1994:38). Bu durum Iran tarafından o dőnemde Sovyetler Birliği gibi süper bir devlete karşı koymanın mümkün olmadığı gibi bir tezle açıklanmaya çalışılmışır.

\section{E. Türkmenistan}

Türkmenistan'ın Hazar'a ilişkin tutumu, uzunca bir süre diğer kıyıdaş devletlere göre daha belirsiz ve esnek olmuştur. Türkmenistan, Rusya ile Iranın baskıları nedeniyle önce bu ülkelerin görüşüne yakın bir görüşü Ocak 1997 tarihine kadar savunmu̧ ve kıyıdaş ülkelere bırakılacak 45 millik münhasır yetki alanı dışında kıyıdaş devletlerin ortak kullanımına açık bir alan tesis edilmesi gercktiği görüşünü benimsemiştir 
(Shoumikhin, 1996b:2). Türkmenistan daha sonra bu gơrüşünü değiş̧irmiş ve idari paylaşımın orta hat esasına göre yapılması, ayrıca kıyıdaş beş ülkenin Hazar'ın kendi sektörlerinde kalan bölümünde mineral kaynaklanı münhasıran kullanmakta serbest olması gerektiği görủşünü savunmaya başlamışur.

Ocak 1997'de Türkmenistan Cumhurbaşkanı Saparmurat Türkmenbaşı Azeri ve Çırak petrol sahalarının Azerbaycanlılarca konan isimlerini değiştirmiş ve kendi adını vermiştir (Nugman, 1998:88). Bu petrol sahaları, 45 millik kıyı şeridinden daha otede olduğu için Türkmenistan'ın Hazar'ın fiilen ulusal sektörlere bölünmesini desteklediği söylenebilir. Ancak işin ilginç' tarafı Hazar'da aynı tezi savunmaya başlayan Türkmenistan ile Azerbaycan, petrol sahalan yüzünden kendi aralarında anlaşmazlı̈̆a düşmüşlerdir.

Fakat son zamanlarda Türkmenistan'ın tekrar tutum değiş̧̧irdiği gözlenmektedir. Türkmenistan Cumhurbaşkanı Saparmurat Türkmenbaşı'nın 6-9 Temmuz 1998 tarihlerindeki Tahran ziyareti sırasında yayımlanan ortak bildiride, Hazar'ın statüsü konusunda kıyıdaş devletlerin onayladığı bir anlaşma ortaya çıkana kadar Iran ve Sovyetler Birliği arasında imzalanan anlaşmalanın geçerli olacağı belirtildi (Radikal, 1998:10). Böylece Türkmenistan, Hazar'ın hem deniz tabanının hem de su kütlesinin ortak kullanımunı savunan Iran'ın görüşlerine daha yakın hale gelmiştir.

Türkmenistan'ın Rusya-Kazakistan Anlaşması sornasında Iran ile belirli őlçüde ortak bir tepki sergilemesinin ardindaki en onemli etken, bu ülkenin Azerbaycan ile Hazar'daki tartışmalı petrol sahalarından kaynaklanan sorunların çözümlenmesinin bir süre daha mümkün olmayacağı düşüncesi ve Azerbaycan'a karşı bir destek arayışı içinde olması şeklinde, açıklanabilir. Bununla birlikte Türkmenistan'ın tutumu halen çok açık değildir. Üstelik Türkmenistan kıyılanna $104 \mathrm{~km}$ uzaklıkta bulunan Serdar/Kepez petrol sahası üzerindeki tek taraflı egemenlik iddiasından vazgeçmiş değildir.

\section{Hazar'ın Deniz veya Göl Statüsünde Değerlendirilmesi}

Hazar'ın göl veya deniz olarak tanımlanması, hukuksal açıdan bir hayli farklı sonuç doğuracakur. Bu nedenle her iki olasılık değclendirilecektir.

\section{A. Hazar'ın Deniz Statüsünde Değerlndirilmesi}

Hazar'ın deniz veya göl olarak hukuksal statüsünün belirlenmesinde sırasıyla şu ụç yola başvurulabilir. Bunlar; Hazar'a ilişkin bugüne kadar yapıılan anlaş̧malar, en gelişmiş deniz hukuku kurallarını koyan 1982 BMDHS ve Hazar'a ilişkin olarak oluşmuş yapılageliş kurallannın saptanması.

Bölüm I'de incelendiği gibi, bugüne kadar Hazar'la ilgili dört temel antlaşma yapılmıştır. Bu antlaşaların birinde Çarlık Rusyası diğer üçünde Sovyetler Birliği tarafken, Iran her dört antlaşmaya da taraftur. Sovyetler Birliği'nin dağılmasından sonra ortaya çıkan dört yeni kıyıdaş devlet (Rusya, Azerbaycan, Kazakistan, Türkmenistan), Aralık 1991'de yayınladiklan Alma-Ata Bildirisi ile selef devlet Sovyetler Birligi'nin yaptığı tüm antlaşmalarla halcf (ardıl) devlet olarak bağlı olduklarını bildirmiş̧erdir (Schofield, 1996:78). Dolayısıyla tüm kıyıdaş devletler Hazar'la ilgili antlaşmalara bağhı durumdadır. Ancak en yenisi 1940'ta yapılmıs olan bu antlaşmalar Hazar'ın statüsünü açıklığa kavuşturmaktan oldukça uzaktur. 1935 Anulaşmasıyla sadece 10 millik kıyı şeridi 
balıkçılık alanı olarak belirlerımiş ve 1940 Antlaşması da bunu teyit etmiştir. Bunun otesinde deniz tabanı ve su küllesiyle ilgili bir düzenleme yoktur. Zaten kıta sahanlığı kavramı $1945^{\prime}$ ten sonra ortaya atılmış ve gelişmiştir. Dolayısıyla bu antlaşmaların fiilen bir işlerliği yoktur.

Deniz hukuku hakkında en son düzenlemeleri içeren 1982 BMDHS'ye müracaat etmek konu açısından yararlı olacaktır. 16 Kasım $1994^{\prime}$ te yürürlüğe giren bu sőzleşmeyi Hazar'a kıyıdaş hiçbir devlet onaıllamamışur. Bunlardan sadece Iran ve Rusya Federasyonu sözleşmeyi imzalamı̧̧ ama onaylamamışır. Ancak bu devletler, sözleşmenin yapılageliş kuralı kaynaklı ve itiraz etmedikleri hükümleri ile bağlıdır.

1982 BMDHS'nin 122. maddesinde "kapalı ve yan kapalı deniz, iki veya daha fazla devlet tarafından etrafı çevrilmiş ve başka bir denize veya okyanusa dar bir çıkışla bağlanan veya tamamen veya esas itibariyle iki veya daha fazla sayıdaki kıyı devletinin karasuları ve münhasır ekonomik bölgesinden oluşan bir körfez, havza veya deniz, manasına gelir" şeklinde tanımlanmıştır (Gündüz, 1994:330). 123. maddede, kapalı ve yarı kapalı denize kıyısı olan devletlerin sözleşmeden doğan haklarını kullanırken ve görevlerini yerine getirirken birß̈irleriyle işbirliği yapmalan öngörülmektedir.

Bu tanıma göre Hazar'ın kapalı veya yarı kapalı deniz statüsünde kabul edilmesi, Hazar'ı Karadeniz ve Baltuk Denizi'ne bağlayan yapay' kanalların uluslararası su sejimine tabi olmalan sonucunu doğuracılktır. Ancak gerek Sovyetler Birliği döneminde ve gerekse bugünkü Rusya Feredasyonu döneminde bu kanallar iç sular rejimine tabidir ve bulunduğu ülkenin bu kanallır iizerinde münhasır yetkileri var olagelmiştir. Zaten Rusya'nın Hazar'ın deniz olmas ına sürekli olarak itirazı vardır. Eğer Rusya Hazar'ı deniz olarak kabul ederse Don-Volga ve Volga-Baltuk kanallarinda uluslararası suyolu rejimini uygulamak zorunda kalacakur (Dion, 1998:81). Bu durumda Hazar'a kıyısı olan diğer devletler bu kanallardan transit g̣eçiş yapma hakkına sahip olabileceklerdir.

Diğer yandan Sovyetler Birliği'nin halefi durumunda bulunan Azerbaycan, Türkmenistan ve Kazakistan'ın, kazanılmı̧ haklar (acquired rights) ilkesi gereğince, bu kanallardan transit geçiş yap̣ma hakkına sahip olmaları gerekmektedir. Bu uygulama Hazar deniz statüsünde olmasa bile halef devletler için geçerli olmak durumundadır. Iran da daha önceki uygulamalar olçüsünde kanallardan geçiş yapma hakkına sahip olabilecektir. Aynca 1982 BMI.HS'nin 124. maddesine göre Azerbaycan, Türkmenistan ve Kazakistan coğrafi bakımdan elverişsiz. ülke konumundadır ve bu açıdan kanallardan serbest geçiş yapma hakkına sahip olmaları gerckmektedir. Kıyıdaş devletler bu sözleşmeyi onayladıkları zaman ilgili madde Hazar için uygulanabilecektir.

Bölüm II'de Hazar'a kıylsiı olan devleLerin görüşleri belirtilmişti. Bunlardan sadece Kazakistan, Hazar'ın deniz oldığınu ve bundan dolayı 1982 BMDHS'nin uygulanması gerektiğini söylüyordu. Ancak Kazakistan'in Şubat 1998'de Rusya ile vardığı anlaşma, Hazar'ı göl gibi değerlendirdiği izlenimini uyandırmaktadır (Aksay, 1998a:7) Hazar'ın deniz olduğunu savunan ikinci bir devlet de Azerbaycan'dır. Ancak Azerbaycan öncelikle Hazar'ın bir "sınır gölü" olduğunu iddia etmekte ve ikinci bir seçenek olarak Hazar'ın deniz olduğunu kabul edebilece ğini sőylemektedir (Gökay, 1998:57). Zaten Azerbaycan için ơnemli olan Hazar'ın göl veya deniz statüsünde olması değil kendi egemenlik alanının tanınmasidır. 
Diğer kıyıdas devletlerden Rusya, Iran ve Türkmenistan Hazar'ı ortak kullanım ilkesinin geçerli olduğu bir göl gibi değerlendiriyorlar. Ayrıca 1935 Antlaşması her ne kadar Hazar için "Sovyet-Iran Deniżi" nitelemesi yapmışsa da 1991'e kadar kıyıdaş olan iki devletin Hazar'a sınır gölü muamelesi yapuklar görülmektedir. Dolayısıyla kıyıdaş devletler Hazar'ın göl olduğu konusunda rahatıkla mutabık kalabileceklerdir. Ancak esas tartışma da Hazar'ın sınır gölü mü yoksa ortak mülkiyetin olduğu bir göl mü olacağı konusunda yoğunlaşmaktadır.

\section{B. Hazar'ın Göl Statüsünde Değerlendirilmesi}

Uluslararası göllerin kullanımına ve paylaşımına iliş̧in geniş geçerliliği olan uluslararası hukuk kurallanının varlı̆̆ından sőzetme olanağı yoktur (Pazarcı, 1990:257). $\mathrm{Bu}$ yüzden kıyıdaş devletlerin uzlaşması önem taşımaktadır. Bugüne kadar Hazar'ın kullanımı ve paylaşımı için iki önemli öneri vardır. Bunlardan biri "condominium" (ortak mülkiyet) olarak da belirtilen ortak egemenlik görüşü, diğeri ise sektörel paylaşım görüşüdür. Tarafların tezlerinin doğruluğunun gözden geçirilmesi açısından tarihi uygulamalara (historical practice) bakmak gerekmektedir. Böylece, bölgesel nitelikli yapılageliş (teamül) kurallarına ulaşmak mümkün olabilecektir.

\section{Hazar'a Ilişkin Tarihi Uygulama}

Azerbaycan Meclis Başkanı Rasul Guliyev, Aralık 1995'te Tahran'da yapılan Hazar ülkeleri konferansında, önemli bir iddia ortaya atmışur (Akimov, ?:2). Guliyev'e göre, 1950'lerin başında Sovyet yetkilileri Hazar'ı scktorlere bölmüştür. Bu yaklaşım hem merkezi Sovyet hükümetinin ve hem enerji (petrol ve doğalgaz), ekonomi (balıkçılık) ve ulaşım alanları dahil Hazar'da faaliyette bulunan pek çok bakanlığın faaliyetlerinden açıkça ortaya çıkmaktadır.

1964 yılında Iran ve Sovyetler Birliği Hava Anlaşması imzalamışlardır (Dabiri, 1994:32-33). Bu anlaşmada Hazar'ın hava sahasına iliş̧kin hiç bir atıf veya düzenleme yapılmamışur. Ancak anlaşma ile o dönemde iki ülkenin kara sularının uç noktalarından (Astara-Azerbaycan, Hüseyinguli (Esen-Guli)-Türkmenistan) düz bir çizgi çizilerek Hazar için FIR (uçuş bilgi bölgesi) hattı belirlenmiştir. Astara-Hüseyinguli FIR hatu Hazar'ın paylaşımı anlamına gelmese de, o dönemde her iki devletin Hazar'la ilgili sınır konusundaki anlayışlarının ortaya konmasında dolaylı bir kanıt niteliğinde değerlendirilebilir.

Benzer şekilde yine 1950-60'lı yıllarda Sovyetler Birliği Bakủ kıyılannın 10 millik kıyı şeridinin açıklarında petrol çıkarmışııı. Ancak tran bu durumu hiç bir şekilde kınamamıs, üstelik Hazar'ın kendi kıyılarına yakın kesimindeki deniz tabanında ve su alanında tek taraflı faaliyetlerde bulunmuştur (Clagett, 1994:3). Bu da tran'ın zımni olarak, Astara-Hüseyinguli çizgisini Hazar'da kendi egemenlik alanı gibi kabullendǐ̆ izlenimini uyandırmaktadır.

Yine 1971-91 dönemi incelendiğinde, Sovyetler Birliği ve Iran'ın fiilen AstaraHüseyinguli bollünmesinin kabul ettikleri yolunda uygulamalar vardır. Bu dönemde Sovyetler Birlił̆i; Azerbaycan, Kazakistan ve Türkmenistan Cumhuriyetleri açıklanında petrol ve doğalgaz aramaları yapmıştır. Yine Sovyetler Birliği Hazar'ın kuzey kesimindcki canlı kaynaklardan tek tarafıı olarak yararlanmıştır. Iran 1991 öncesi dönemde Hazar'la çok az düzeyde ilgilenmiştir (Gustafson, 1995:14). 
1970'li yıllarda Sovyeder Birliği Hazar'ın kuzeyini Azerbaycan; Kazakistan, Rusya ve Türkmenistan Sovyet Cuınhuriyetleri arasında eşit uzaklık ilkesine göre iktisadi bölgelere ayırmışır. Bu paylaşın sırasında eğer kıyı açıklarında adalar varsa, Hazar'a iliş̧kin sınırın belirlenmesinde $\mathrm{o}$ ada kıyıları esas alınmışır. Bu dönemde Rusya dahil hį̣ bir Sovyet Cumhuriyeti böyle bir paylaşıma tepki göstermedikleri gibi, tran da herhangi bir protestoda bulunmamıştr (Kephanov, 1997-98: 14).

Hazar'ı bu şekilde paylaşilmasıyla, Kazakistan 113.000 km kare, Rusya 64.000 km kare, Azerbaycan ve Tưrkmenistan yaklaşık $80.000 \mathrm{~km}$ karelik bir alana sahip duruma geldiler (Yusifzade, 1994:2). Her Sovyet cumhuriyeti kendi alanı içerisinde petrol ve doğalgaz araması ile her türlij araştırma yapma konusunda münhasır haklara sahip olmuştur.

Bu paylaşım, Kasım 1993'te Astrahan'da düzenlenen bir seminerde Rusya Feredasyonu Başbakanı Vicıor Chemomyordin'in açıklamasıyla da onaylanmışur (Yusifzade, 1998:2). Yine Sovyetler Birliği dağıldıktan kısa bir süre sonra eski Sovyet Cumhuriyetleri biraraya gele:rek: Hazar'ın sektörlere bölünmüş halini tanımışlardır (Akimov, ?:2).

1992'nin başında Rusya Pctrol Sảnayisi Bakanlığı yeni oluşan devletler arasında Hazar'da petrol sahalarının böliunnesiyle ilgili bir direktif yayınlamıştır (Croissant, 199697:29). Moskova aynca Hazar'in tabanını ayn ulusal enerji sektơrlerine bőlmüştür ve Rusya Enerji Bakanlığı bu böliınmeyle ilgili anlaşmalar imzalamıştır.

Gơrüldüğä gibi, geçmił dönemdeki uygulama Hazar'ın bir sınır gölü olduğunu tescil etmektedir. 1991 'e kadar Iran ve Sovyetler Birliği kendi aralarında fiilen aşağı yukarı Astara-Hüseyinguli çizg isine denk düşen bir sınırı Hazar için belirlemiştir. Ya da en azından uygulamalanyla biiyle bir sınırın varlı̌̆ını zımni olarak kabullenmişlerdir. Sovyetler Birliği bu çizginin kuzeyindcki bölgede pek çok tek taraflı tasarrufta bulunmakla kalmayıp 1970'ler(le cumhuriyetler arasındaki sının da eşit uzaklık ilkesine göre çizmiştir. Sovyetler Birliği'nin dağılmasından hemen sonra da Rusya ve Iran tarafindan benzer bir tutum serpilenmiştir. Ancak Rusya ve Iran 1993'ten sonra Hazar'a ilişkin politikalanın değiştirerık ortak egemenlik fikrini ortaya atmışlar ve sektörel paylaşım uygulamasını reddetmişlerdir.

Son olarak Hazar'ın yałın geçmişte bir sınır gölü olarak değerlendirildiği ve sektörel olarak da paylaşıı̀ldığı yolunda bir sonuca varılmaktadır. Bu da Hazar'a ilişkin olarak sektörlere bőlünmüş bir göl olduğu yönünde bölgesel bir yapılageliş (teamül) kuralının varlığını desteklemekt:dir.

\section{Hazar'ın Sınırlandırılması Yöntemi}

Hazar'ın sınırlandırılması için, ele alınabilecek iki yöntem vardır. Bunlardan biri ortak kullanım ilkesini kabul edip bu çerçevede bir sınıllandırmaya gitmek, ikincisi ise Hazar'ın sınır gölü gibi tamamen paylaşılmasıdır.

Uluslararası hukukta ortik egemenlik rejimi genel olarak condominium (ortak mülkiyet) şeklinde belirtilir. Rusya ve Iran Hazar'da ortak egemenlik görüş̧ünü desteklemektedir. Uluslararası hukukta kapalı bir su havzası üzerinde ortak mülkiyete 
sadece El Salvador, Honduras, Nikaragua arasındaki Fonseca Körfezi örneğinde rastlanmaktadır. Her ne kadar ortak mülkiyet genelde ilgili taraflar arasındaki anlaşmayla belirleniyorsa da Fonseca körfezi örneğinde ortak mülkiyet Uluslararası Adalet Divanı'nın (UAD) bir kararının sonucu gerçekleşmiştir. Divan Körfez'in eskiden tek bir devlete Ispanya- ait olması ve uzun bir süredir bütün bir su kütlesi olarak değerlendirilmesini göz önüne alarak, halef devletlerin Fonseca Körfezi'ni ortak kullanmasına karar vermiştir (Dabiri, 1994:46). Ancak bu örneğin Hazar'a uygulanması mümkün değildir, çünkï öteden beri Hazar'da birden fazla kıyıdaş devleter olagelmiştir.

Hazar'ın ulusal sektörlere bőlünmesi ise daha geniş bir hukuksal geçerliliğe sahiptir. Ancak bölünmenin nasıl yapılacağı diğer bir sorundur. Yukarıda da bahsedildiği gibi uluslararası hukuk iki veya daha fazla devlet arasında bir sınır oluşturan göllerin kullanımı ve paylaşımına ilişkin herhangi bir düzenleme getirmemiştir. Bu noktada benzeri durumlardaki uygulamalar bir örnek teşkil edebilecektir. Devletler sınurlandırma ile ilgili olarak anlaşarak istedikleri düzenlemeye gitmekte serbest olmalanna rağmen, pek çok anlaşmada sınır gölleri ile ilgili olarak orta hat/ eşit uzaklık (median line/equidistance line) ilkesinin uygulandığı görülmcktedir. Ömeğin Büyük Kuzey Amerika Gölleri daha 1783 yılında orta hat ilkesine göre sınırlandırılmıştır (Clagett, 1995:8). Bu konuda diğer örnekler ise şunlardır: Viktorya Gölü (Kenya, Tanzanya, Uganda), Malawi Gölü (Malawi, Mozambik), Cenevre Gölü (Fransa, Isviçre), Çad Gölü (Nijerya, Nijer, Çad, Kamerun) (Schoficld, 1996:78).

Iki veya daha çok devletin kıyıdaş olduğu kapalı bir deniz veya göle iliş̧in sınırlandırma sőzkkonusu olduğu zaman orta hat ilkesi adil ve hakkaniyete uygun ve karar verilmesi açısından önemlidir. Bu konuda Almanya Federal Mahkemesi tarafından 1920 yılında karara bağlanmış olan Constance Gölü davasında da orta hat uluslararası hukukun genel bir ilkcsi olarak kabul edilmiştir (Clagett, 1995:8).

Kıta sahanlığının belirlenmesinde orta hat esası sıkça kullanılan bir yöntemdir. 1958 Kıta Sahanlığı Sözleşmesi'nde bir anlaşmanın olmaması durumunda özel durumlar çerçevesinde başka bir yola gidilmedikçe kıta sahanlığı sınırının belirlenmesinde orta hav/eşit uzaklık ilkesinin uygulanacağı ifade edilmcktedir (Clagett, 1995:8). Ancak bu ilkeden 1982 BMDHS'de vazgeçilmiştir. 1982 BMDHS'ye göre, kıyıları karşı-karşıya veya yan-yana olan devletler arasında kıta sahanlığının sınırlandınıması, hakça bir çözüm (equitable solution) bulmak üzere, UAD Statüsü'nün 38. maddesinde belirtilen hükme görc anlaşma ile belirlenecektir (Gündüz, 1994:319).

1969 Kuzey Denizi Kıta Sahanlığı davalarında önemli olan bir başka husus da Mahkemenin deniz. sınırlarının belirlenmesinde her bir devletin kıyı şeridi uzunluğu ile orantılı olarak deniz sularından faydalanmasını sağlayacak bir sonuca ulaşıımasını temel kıstas olarak belirlemiş olmasıdır. Sözkonusu davalarda orta hat ilkesinin uygulandığı bazı durumlarda kıyı uzunluklarınà orantılı olmayan adaletsiz sonuçların ortaya çıkabileceği vurgulanmıştır. Bu durumda deniz hukuku bitişik veya karşıılıklı kıyılarda sınırlandırmanın adil bir çözü̈m sağlanacak şekilde yapılması gerektiğini belirtmektedir (Clagett, 1995:8). Burada orantllhlk ilkesi, orta hat ilkesinin adil olmayan sonuçlarını dengeleyen bir unsur olarak orlaya çıkmaktadır.

Bitişik kıyıların sınırlandırılmasına iliş̧in olarak iki ayrı yőntem daha bulunmaktadır: Kıyının genel yönüne dikey bir çizgi çizilmesi ve iki devletin kıyı çizgisinin oluşturduğu açının ikiye bölünmesi. Ancak, karşılıklı sınırlandırma sözkonusu 
olduğunda ve kıyı çizgilerinin bijyük olçüđde orantısız olmadığı durumlarda tercih edilen yöntem orta hatur. Esasen yukırıda söz edilen diğer iki sınırlandırma yöntemi bitişik suların sınırlandırılması için geliş̧irilmiştir ve fiziksel olarak karşılıklı suların sinurlandırılmasına firsat vermemektedir (Clagett, 1995:9).

Sınırlandırma konusundalıi düzenlemelerde, genelde bu üç yöntemden birine veya daha fazlasına başvurularak geçici sınırlar tespit edilmektedir. Karşılıklı devletler arası sınırların belirlenmesi sözkonusu olduğunda orta hat yöntemi kullanılarak geçici sınırlar belirlenir. Daha sonraki aşama bu sınırların hakkaniyete uygun ve orantılı olup olmadığının ortaya çıkartılmasıdır. Gerek duyulursa bu hesaplama sayısal olarak yapılabilir. Burada-mevcut kıyıların uzunlukları ve kıyıdaş devletlerin payına düşen deniz alanı belirlenir. Daha sonra bu iki rakam arasındaki orantıya bakılır.

Orantılık ilkesinin yanısıra gözönünde bulundurulabilecek bir başka unsur bu konuda geçmişten bu yana yapılan uygulamadir. Bir devletin parçalanarak birden fazla devlet haline gelmesi durumunda mevcut idari sınırlar uluslararası sınırlar olarak kabul edilmektcdir.

Hazar'a gelince, bu yöntemlerden hem karşılıklı hem de bitişik sular için yapılan uygulamalar degerlendirilmelidir. 'Zira Hazar'ı kuzey, orta ve güney olarak üç bölüme ayırmak mümkündür (Dion, 1998:80). Hazar'ın kuzey kesimi Rusya ve Kazakistan arasında paylaşılmış bulunmaktadır. Hazar'da bu iki devletin egemenlik alanlarının belirlenmesi için hem bitişik heriı de karşılıklı sular için uygulanması gereken yőntemler uygulanabilecektir. Bu açıdan R.usya ve Kazakistan'ın Nisan 1998'de kendi aralarında anlaşarak "pragmatik orta hat" esasına göre bir sınır belirlemeleri, Hazar'ın üç bölümlü ozzelliğinin doğal bir sonucudur (BBC, 1998a:6). Rusya'nın Azerbaycan ve Kazakistan'ın Türkmenistan ile olan yan deniz sının yine bitişiklik esasına göre belirlenecektir.

Hazar'n orta kesiminde ycr alan Azerbaycan vo: Türkmenistan'ın sınırlan tamamen karşılılık esasına göre belirlenecı.ktir. Bakü ve Aşgabat üçüncü devletlerin müdahalesine gerek kalmaksızın sınırı kendi aralarında belirleyebilirler ve Kepez/Serdar petrol yataklarının kime ait olduğu sorınınu çözebilirler ${ }^{2}$. Rusya ve Kazakistan arasında ikili bir anlaşma imzalanması, Türknienistan ve Azerbaycan arasında da ikili bir anlaşmayla Hazar'ın statüsünün belirlenmesi konusunda en azından uygulamada ornek bir durum ortaya çıkarmışır. Ancak burada sorun bu ikili anlaşmalarda statüye ilişkin farklı düzenlemelere gidilmesi durumunda ortaya çıkacaktır. Aynı göl veya denizde iki farklı düzenlemeye gidilmesi, uygulamada bir çok hukuksal ve siyasi sorunu beraberinde getireccktir.

\footnotetext{
2Türkmen yetkililerce, SSCB zamanında orta hat esasına göre çizilmiş bulunan ve Azerbaycan-Türkmenistan sınırını gösteren çizgi esas alındığı taktirde "Yuzyılın Anlaşması"nın konusunu oluşturan Çırak yatağının yarısının ve Azeri yatağının tamamının Türkmenistan'a ait kesiminde kaldığ!̣, bu itibarla Türkmenistan'a ait olduğu iddia edilmiştir (Kepbanov, 1997-98:14). Yine Türkmen sahiline $104 \mathrm{~km}$, Azerbaycan sahiline ise $184 \mathrm{~km}$ mesafede olan Kepez (Azerbaycanca)/Serdar (Türkmence) bölgesinde Azerbaycan'ın hak iddia etmesine Türkmenistan oldukça sert tepki göstermiştir (Dion, 1998:82). Bu sorun halen çözün:lenememiştir.
} 
Hazar'ın güney kısmındà tek başına Iran yer almaktadır. Astara-Hüseyinguli (EsenGuli) çizgisinin güneyinde yer alan Iran'ın egemenlik bölgesinin Azerbaycan ve Türkmenistan ile olan sının ise bitişik sulara uygulanan yöntemlerle çözülecektir.

Bu çerçevede Iran hariç Hazar'daki idari sınırlar yukarıda belirtildił̆i gibi, 1970'li yıllarda Sovyetler Birliği tarafından çizilmiştir. Bugün bu sınırlar geçici olarak kabul edilip adil ve hakkaniyete uygun olarak kıyıdaş devletler arasındaki sınırlarda küçük düzenlemelere gidip Hazar'daki kesin sınırlar saptanabilir. Kahıcı sınırların saptanmasında Hazar'a ilişkin olarak iki sorun gündeme gelecektir.

Bunlardan ilki Hazar'da sınırlar belirlenirken kıyıların mı yoksa adaların mı gözönüinde bulundurulacă̆ıdır. Ikincisi ise sürekli değişen deniz seviyesinde paylaşım konusunda nasıl bir ơlçüt saptanacağıdır.

Hazar'daki sınırların belirlenmesinde anakaranın mı yoksa adaların mı esas alınacağı konusunda geçmiş uygulamalarda bir çozü̈m bulunmaktadır. 1970'lerde Sovyetler Birligi tarafindan Cumhuriyetler arasında belirlenen idari sınırlar adaların kıyılan esas alınarak saptanmışır (Yusifzade, 1994:2). Her ne kadar Sovyetler Birliği'nin tek taraflı tasarrufu olduğu için Iran açısından bu uygulamanın hiç bir bağlayıcılığı olmasa da, sorunun çözümünde geçmiş uygulamalardan da yararlanılabilir.

Hazar'ın sulan 1978'den beri her yll yaklaşınk $10 \mathrm{~cm}$ yükselmektedir (Schofield, 1996:75). Su seviyesinin yükselmesi bir çok çevrc sorunlanına yol açtı̆̆ı gibi, Hazar'daki sınınn saptanmasını güçleştirmektedir. Zira Hazar'ın doğu yakası batı yakasından daha düz olduğu için, Hazar'ın genişlemesi daha çok doğuya doğru olmaktadır (Gustafson, 1995:15). Bu durumda 1978'den beri Hazar'ın orta noktası sürekli doguya dogru kaymakıadır. Bundan en karlı çıkan devletler Azerbaycan ve Rusya iken, doğu yakasındaki Türkmenistan ve Kazakistan su seviyesinin yükselmesinden zarar görmektedir. Bu ozel duruma ilişkin olarak, sınır saptanması konusunda uluslararası hukukta genel geçerliliğ̈i olan bir kural bulmak zordur. Dolayısıyla sürckli ve eşitsiz olarak yükselen su seviyesi karşısında, Hazar'a kıyıdaş devletlerin adil ve hakkaniyete uygun bir sınır belirlemeleri en uygun çözüm olacaktır. Bu tür sorunların çözümünde, kıyıdaş beş devlet tarafından kurulan ve Ekim 1998'de Bakü'de merkezi açılan Hazar Merkez Grubu (Caspian Center Group) arabulucu ve eşgüdüm sağlayıcı bir görev üstlenebilir (Avrasya Dosyası, 1998:3).

\section{SONUÇ}

Hazar, büyüklüğünden ve suyunun tuzlu olmasından dolayı tarih boyunca sürekli deniz sıfatıyla anılmışur. 1935'te Sovyetler Birliği ve Iran arasında yapılan antlaşmayla Hazar bir "Sovyet-Iran Denizi" olarak tanımlanmışur. Ancak Hazar'ın doğal kanallar veya boǧazlarla açık denizlcre çıkışının olmayışı onun göl olarak değerlendirilmesine de yol açmıştır. Ancak Hazar üzerindeki tarış̧malar, onun göl veya deniz olmasında değil, ne şekilde paylaşılıp kullanılacağı üzerinde yoğunlaşmışur. Özellikle 1991'de Sovyetler Birliği'nin dağılıp ortaya yeni kıyıdaş devletlerin çıkması ve bu yeni devletlerin Hazar'daki petrol ve doğalgaz yatakların işlemeye açmaları beraberinde büyük tarışmalar getirmiştir. Günümüze kadar Hazar'ın paylaşımına ilişkin kesin düzenlemelerin olmaması, bu tartışmaları daha da körüklemiştir. 
Bugüne kadarki tarihi uvgulamalara bakıldığında, Hazar'ın bir sınır gölü oldugu ve burada sektörel paylaşımın esas olduğu konusunda bir yapılageliş kuralının olduğu izlenimi doğmaktadır. Aynca Hazar'ın kendine özgï (sui generis) రzelliğe sahip bir göl olduğu ortaya çıkmaktadır. Ancak bu Hazar'ın ulusal sektörlere bölünmesine engel değildir. Kıyıdas devletler Hazar'in sui gereris özelliğinden dolayı ozellikle çevre sorunlarının çozümü konusunda sıkı bir işbirliği yapmak zorundadırlar. Ayrıca su seviyesinin sürekli yükselmesi çevre sorunları çıkarmasının yanısıra, ulusal sınırların saptanmasını güçleştirmektedir. Bu nedenle kıyıdaş devletler kesin sınırların belirlenmesi için adil ve hakkaniyete uygun şözümler üretmeleri gerekmektedir.

Sonuç olarak, Hazar'daki mevcut hukuksal sorunlar nasıl çőzullürse çőzülsün, deniz hukukunun dolayısıyla uluslararası hukıkun gelişimine büyük katkı sağlayacaklardır.

\section{KA YNAKÇA}

Akgün, M. (1998) "Hazar'ın Statïsü", Yeni Yüzyıl, 9 Temmuz.

Akimov, A. (?) "Oil and Gas in the Caspian Sea: An Overview of Cooperation and Conflict". Institute of Oriental Studies, Russian Academy of Sciences. http://www'.nussian.org/pub/ćaspiansea.html. (23.07.1997).

Aksay, H. (1998a) "Hazar Kıyılarında Anlaşmak Kolay Değil", Cumhuriyet, 13 Nisan.

Aksay, H. (1998b) "Hazar Denizi'nde Sular Isınıyor", Cumhuriyet, 13 Temmuz.

Aleksandrov, V. (1997) "Ecological Problems of the Black Sea", International Affairs, Vol. 43, Nc. 2, s. 87-99.

Arystanbekova, A. (1998) "Oceans and the Law of the Sea", United Nations General Assembly Fifty-Second Agenda Item 39, A/52/802, 24 February.

Avrasya Dosyası (1998) "Caspian Center Group", sayı: 107, Eylül 98/2.

BBC (1998a) "Russia and Kazakhstan", Summary of Worid Broadcasts, Part I Former USSR, SUW/1)5:36 WF/2, 8 May.

BBC (1998b) "Iran, Kazakhstan Differ over Caspian Status", Summary of Worid Broadcasts, Part I Former USSR, SU/3240 G/3, 22 May.

BBC (1998c) "UN Documents Iran's Protest at Russian-Kazakh accord on Caspian Sea", Summary of World Broadcasts, Part I Former USSR, SUW/0536 WF/2, 30 May.

Bilici, A. (1998) "Petrolü, Doğalgazı, Havyarı Var Statüsü Yok", Aksiyon, 30 Mayıs5 Haziran, s. 42-44.

Bremmer, I. (1998) "Oil Politics: American and the Riches of the Caspiana Sea", World Policy Journal, Spring, s. 27-35. 
Clagett, B. M. (1995) "Ownership of the Seabed and Suboil Resources in the Caspian Sea under the Rules of International Law", Caspian Crossroads, No. 3, Summer-Fall, s. 3-12.

Clawson, P. (1997-98) "Iran and Caspian Basin Oil and Gas", Perceptions, Vol. 2; No. 4, December-February, s. 353-367.

Croissant, C. M., M. P. Croissant (1996-97) "Hazar Denizi Statüsü Sorunu: Içerił̧i ve Yansımaları", Avrasya Etütleri, Kış, s. 23-49.

Croissant, M. P. (1997) "US Interests in the Caspian Sea Basin", Comparative Strategy, Vol. 16, No. 4, October-December, s. 353-367.

Dabiri, M. R. (1994) "A New Approach to the Legal Regime of the Caspian Sea as a Basis for Peace and Development", The Iranian Journal of International Affair, Vol. 6, No. 1-2, Spring-Summer, s. 28-46.

Dion, R. R. (1998) "Cutting up the Caspian", The World Today, March, s. 80-82.

Gökay, B. (1998) "Caspian Uncertainties: Regional Rivalries and Pipelines", Perceptions, March-May, s. 49-66.

Gustafson, T., A. Reteyum, L. Ruseckas (1995) "The Caspian Sea: Whose Waters? Whose Oil?, Cambridge Energy Research Associates, July, s. 1-26.

Gündüz, A. (1994) Milletlerarası Hukuk ve Milletlerarası Teşkilatlar Hakkında Temel Metinler, Istanbul, Beta Yayınevi.

Hiro, D. (1997a) "Why is the US Inflating Oil Reserves?", Middle East International, 12 September, s. 18-19.

Hiro, D. (1997b) "Azeri Oil", Middle East International, 21 November, s. 16-17.

Holoboff, E. (1996) "Russia and Oil Politics in the Caspian", Jane's Intelligence Review, February, s. 80-84.

Kepbanov, Y. A. (1997-98) "The New Legal Status of the Caspian Sea is the Basis of Regional Cooperation and Stability", Perceptions, Vol. 2, No. 4, December-February, s. 8-16.

Lenczowski, G. (1997) "The Caspian Oil and Gas Basin: A New Source of Wealth?", Middle East Policy, Vol. 5, No. 1, January, s. 111-119:

Momtaz, J. (?) "The Legal Status of the Caspian Sea": ?. http://www.ipis.org/pub/amurdarya/amu2/momtaz. (10.12.1997).

Nugman, G. (1998) "Hazar Denizi'nin Hukuki Statüsü", Avrasya Etütleri, llkbahar, s. $80-91$. 
Pavilionis, P., R. Giragosian (1996-97) "The Great Game Pipeline Politics in Central Asia", Harward International Review, Winter, s. 24-27.

Pazarcı, H. (1992) Uluslararası Hukuk Dersleri I. Kitap, Ankara, Turhan Kilabevi.

Pazarcı, H. (1990) Uluslararası Hukuk Dersleri II. Kitap, Ankara, Turhan Kitabevi.

Radikal (1998) "Hazar'da Kavi̧a Kızışu", 9 Temmuz.

Schofield, C., M. Pratt (1996) "Claims to the Caspian Sea", Jane's Intelligence Review, February, 3 .75-78.

Shoumikhin, A. (1996a) "Economics and Politics of Developing Caspian Oil Resource", Moscow Public Science Foundation, September Perspectives, Vol. 1, No. 8, November, s. 1-4.

Shoumikhin, A. (1996b) "New Development Related to Caspian Oil", Moscow Public Science Foundation, September Perspectives, Vol. 1, No. 9, November, s. 14 .

Shoumikhin, A (1997) "Develcping Caspian Oil: Between Conflict and Cooperation", Comapative Strategy, Vol. 16, No. 4, October-December, s. 337-351.

Sobhani, S. R. (1997) "The Greal Game in Play in Azerbaijan", The Washington Times, 20 February.

Starr, S. F. (1997) "Power Failure American Policy in the Caspian", The National Interest, Spring, s. 20-31.

Tordai, J. (1998) "Regional Oil Comes on Streams", The Middle East, January, s. 30-31.

Yusifzade, K. (1994) "The Status of the Caspian Sea", SOCAR. Autumn. http://www.azer.com/24. folder/24.statuscaspian.html. (04.05.1998). 